\title{
Maksimalisasi Keuntungan Pada UMKM Sosis Bu Tinuk Menggunakan Metode Simpleks dan POM-QM
}

\author{
Dini Anggun Sari ${ }^{1}$, Erna Sundari ${ }^{1}$, Deshinta Dwi Rahmawati ${ }^{1}$, Rudi Susanto ${ }^{2, *}$ \\ ${ }^{1}$ Fakultas Ilmu Komputer, Program Studi Sistem Informasi, Universitas Duta Bangsa, Surakarta, Indonesia \\ ${ }^{2}$ Fakultas Ilmu Komputer, Program Studi Teknik Informatika, Universitas Duta Bangsa, Surakarta, Indonesia \\ Email: ${ }^{1}$ anggunable6@gmail.com, ${ }^{1}$ ernasundari59@gmail.com, ${ }^{1}$ deshinta11@gmail.com, ${ }^{2 *}$ rudi_susanto@udb.ac.id \\ Submitted 04-01-2020; Accepted 20-02-2020; Published 26-04-2020
}

\begin{abstract}
Abstrak
Saat ini banyak masyarakat yang berlomba-lomba dalam membangun usaha guna memenuhi kebutuhan pokok sehari-hari. Usaha dagang sosis merupakan salah satu usaha dalam bidang kuliner. Tentu saja, pedagang tidak ingin mengalami kerugian dalam usaha bisnisnya. Oleh sebab itu, pedagang harus mempunyai teknik atau metode yang tepat untuk mengembangkan dan memaksimalkan keuntungan bisnis mereka. Dalam penelitian ini menggunakan metode simpleks serta memanfaatkan teknologi informasi yaitu POM-QM dalam memperkirakan keuntungan maksimum yang diperoleh dari setiap produksi yang dilakukan oleh pedagang sosis dalam waktu satu hari sehingga memiliki perkiraan perhitungan yang akurat. Hasil perhitungan keuntungan maksimum yaitu mencapai angka Rp $63.000,00$ per hari.
\end{abstract}

Kata Kunci: Maksimalisasi, Keuntungan, Metode Simpleks, POM-QM

Abstract

Today many people are competing in building businesses to meet their basic daily needs. Sausage trade business is one of the businesses in the culinary field. Of course, the traders doesn't want a lost in their business. Therefore, traders must have the right technique or method to grow up and increased their business profits. This study is using the simplex method and supported by information technology that is POM-QM to estimating the maximum profit gained from each production which is made by sausage trader per day, so that it has an accurate calculation estimate. The calculation of maximum benefit is reaches in $\mathrm{Rp} 63.000,00$ per day.

Keywords: Maximization, Profit, Simplex Method, POM-QM

\section{PENDAHULUAN}

Pada zaman sekarang ini, pertumbuhan perekonomian di Indonesia bertumbuh sangat pesat. Untuk mencukupi kebutuhan sehari-hari masyarakat memikirkan cara untuk membangun usaha. Usaha Kecil Menengah (UKM) merupakan salah satu usaha yang memiliki peranan penting dalam membangun ekonomi di Indonesia [1],[2]. Seiring dengan berkembangnya bisnis yang disertai persaingan yang begitu banyak turut mempengaruhi usaha produksi berskala kecil. Banyak usaha produksi berskala kecil yang setiap harinya harus berjuang supaya usaha yang dibangun tetap berlangsung dan menghasilkan keuntungan.

Usaha dagang sosis adalah salah satu usaha di bidang kuliner, dimana pedagang harus berusaha agar hasil dari usaha dagang sosis nya mampu memberikan keuntungan agar bisa mencukupi kehidupan sehari-hari. Untuk menjaga kelangsungan dan berkembangnya usaha dagang sosis diperlukan cara untuk dapat mengalokasi bahan baku serta meningkatkan keuntungan. Oleh sebab itu, diperlukan teknik atau suatu metode dalam memperkirakan kombinasi yang tepat dari produk yang dibuat serta kombinasi dari produk yang dihasilkan. Untuk mengatasi permasalahan tersebut, penelitian ini menggunakan metode simpleks yang merupakan bagian dari pemrograman linear.

Pemrograman Linear merupakan metode matematik dalam mengalokasikan sumber daya yang terbatas untuk mencapai suatu tujuan seperti memaksimumkan keuntungan dan meminimumkan biaya [3],[4],[5]. Persoalan pemrograman linear dapat ditemukan pada berbagai bidang dan dapat digunakan untuk membantu membuat keputusan untuk memilih suatu alternatif yang paling tepat dan pemecahan yang paling baik (the best solution) [6]. Penelitian ini memanfaatkan teknologi informasi yaitu penggunaan Software POM-QM untuk memperkirakan keuntungan maksimum yang diperoleh dari setiap produksi yang dilakukan oleh pedagang sosis sehingga memiliki perkiraan yang akurat.

\section{METODE PENELITIAN}

Adapun metode atau langkah-langkah dalam penelitian ini adalah sebagai berikut [7],[8],[9]:

1) Identifikasi Masalah

Masalah yang dihadapi oleh UMKM Sosis Bu Tinuk adalah memaksimalkan keuntungan dengan keterbatasan bahan baku berupa sosis dan telur yang dimiliki.

2) Pemilihan Model Pemecahan Masalah

Model yang digunakan dalam pemecahan masalah adalah model pemrograman linear dengan metode simpleks untuk mencari keuntungan maksimum secara manual dan analisis menggunakan software POM-QM.

3) Pengumpulan Data

Pengumpulan data dilakukan melalui studi pustaka, observasi, dan wawancara dengan Bu Tinuk selaku pedagang sosis. Data yang dibutuhkan dalam penelitian ini berupa bahan baku produksi, produksi yang dihasilkan, jumlah produksi, dan keuntungan produksi dalam satu hari.

4) Pengolahan Data dan Analisis 
Pengolahan data dan analisis mengunakan pemrograman linear metode simpleks dan dibantu dengan software aplikasi POM-QM.

5) Implementasi Model

Tahap implementasi model adalah mempersiapkan model matematik pemrograman linear untuk permasalahan maksimasi keuntungan. Pemodelan pemrograman linear dilakukan dengan mengidentifikasi variabel keputusan, fungsi tujuan dan fungsi-fungsi kendala (constraint). Berikut adalah langkah-langkahnya [10]:

a. Mengubah fungsi tujuan dengan batasan, yaitu $C_{j} X_{i j}$ digeser ke kiri. Contoh: $Z=40 X_{1}+35 X_{2}$ menjadi $Z-40 X_{1}-$ $35 \mathrm{X}_{2}$. Kemudian hasilnya dimasukkan ke dalam tabel simpleks.

b. Memilih kolom kunci, yaitu memilih kolom yang fungsi tujuannya memiliki nilai negatif yang terbesar.

c. Memilih baris kunci. Pilih baris yang mempunyai limit rasio dengan angka terkecil. Limit rasio = nilai kanan / nilai kolom kunci.

d. Mengubah nilai baris kunci. Yaitu membagi nilai baris kunci dengan angka kunci, ganti variabel dasar pada baris kunci dengan variabel yang terdapat dibagian atas kolom kunci.

6) Evaluasi Hasil

Evaluasi hasil dilakukan dengan menganalisis hasil analisis pemrograman linear yang dihasilkan oleh software aplikasi POM-QM pada langkah sebelumnya. Evaluasi hasil juga dilakukan dengan membandingkan antara hasil penelitian dengan kondisi aktual yang dialami oleh UMKM Sosis Bu Tinuk.

7) Melaksanakan Solusi Terpilih

Tahap pelaksanaan solusi terpilih bukan bagian dari penelitian, maka langkah pengambilan keputusan hanya sampai pada tahap evaluasi hasil. Tahap melaksanakan solusi merupakan wewenang dari pihak pedagang sosis yaitu Bu Tinuk. Hasil dari pemodelan dapat digunakan sebagai pertimbangan pengambilan keputusan terkait permasalahan produksi yang dialami oleh pedagang, bukan sebagai keputusan yang bersifat mutlak harus direalisasikan.

Langkah-langkah penelitian di atas dapat dilihat dengan jelas pada Gambar 1.

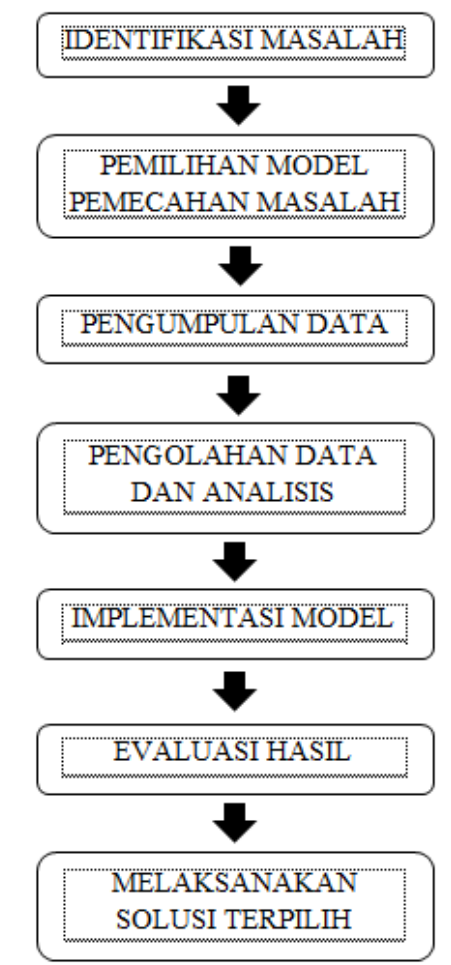

Gambar 1. Diagram Alur Penelitian

\section{HASIL DAN PEMBAHASAN}

Dalam pembuatan sosis, Bu Tinuk dapat memproduksi dua jenis olahan sosis yaitu sostel (sosis telur) ukuran besar dan sostel ukuran kecil. Untuk menjajakannya, Bu Tinuk menitipkan sosis hasil produksinya ke beberapa kantin sekolah. Bu Tinuk dapat memproduksi 15 buah sostel besar dan 15 buah sostel kecil setiap harinya dengan keuntungan kurang lebih Rp 60.000,00. Data bahan/resep dapat dilihat pada Tabel 1 dan data rincian bahan baku pembuatan sosis dapat dilihat di Tabel 2. 
Tabel 1. Data Bahan Pembuatan Sostel

\begin{tabular}{cc}
\hline Bahan & Kapasitas \\
\hline Sosis & 2 bungkus \\
Telur & $1,5 \mathrm{~kg}$ \\
Kaldu Bubuk & 6 sachet \\
Merica Bubuk & 5 sachet \\
Minyak Goreng & $1 \mathrm{~kg}$ \\
Adonan Saus & secukupnya \\
Tusuk Sate & 1 ikat \\
\hline
\end{tabular}

Tabel 2. Data Rincian Bahan Baku Pembuatan Sostel

\begin{tabular}{cccc}
\hline \multirow{2}{*}{$\begin{array}{c}\text { Bahan } \\
\text { Baku }\end{array}$} & $\begin{array}{c}\text { Jenis Produk } \\
\text { Sostel Besar } \\
\text { (buah/butir) }\end{array}$ & $\begin{array}{c}\text { Sostel Kecil } \\
\text { (buah/butir) }\end{array}$ & $\begin{array}{c}\text { Kapasitas } \\
\text { (buah/butir) }\end{array}$ \\
\hline Sosis & 1 & 1 & 30 \\
Telur & 1 & 0,5 & 24 \\
\hline
\end{tabular}

Berdasarkan data bahan baku pembuatan sostel Bu Tinuk dapat dikelompokkan sebagai variabel keputusan yaitu:

1) Sostel besar : membutuhkan 1 buah sosis dan 1 butir telur.

2) Sostel kecil : membutuhkan 1 buah sosis dan 0,5 butir telur.

Keuntungan per produk yang diperoleh adalah :

1) Sostel besar Rp 2.500,00 per buah.

2) Sostel kecil Rp 1.500,00 per buah.

Sedangkan persediaan bahan baku adalah:

1) Sosis 2 bungkus $=30$ buah.

2) Telur $1,5 \mathrm{~kg}=24$ butir.

\subsection{Analisis Data}

Menentukan formulasi dari data di atas menggunakan simbol $\mathrm{X}_{1}, \mathrm{X}_{2}$, dan $\mathrm{Z}$ dimana:

$\mathrm{X}_{1}=$ jumlah sostel besar yang akan diproduksi per hari.

$\mathrm{X}_{2}=$ jumlah sostel kecil yang akan diproduksi per hari.

$\mathrm{Z}=$ jumlah keuntungan sostel besar dan sostel kecil per hari.

Tujuan penelitian ini adalah menentukan jumlah produksi untuk memperoleh keuntungan yang maksimal dari kendala/keterbatasan bahan baku yang dimiliki. Maka formulasi model matematisnya adalah:

Memaksimumkan $\mathrm{Z}=2.500 \mathrm{X}_{1}+1.500 \mathrm{X}_{2}$

Keterbatasan sumber daya dapat dibuat formulasi batasan-batasan sebagai berikut:

a) Banyaknya sosis yang digunakan untuk membuat 1 buah sostel besar $\left(\mathrm{X}_{1}\right)$ adalah 1 buah dan untuk membuat 1 buah sostel besar $\left(\mathrm{X}_{2}\right)$ juga memerlukan 1 buah sosis. Kapasitas sosis adalah 30 buah.

b) Banyaknya telur yang digunakan untuk membuat 1 buah sostel besar $\left(\mathrm{X}_{1}\right)$ adalah 1 butir dan untuk membuat 1 buah sostel kecil $\left(\mathrm{X}_{2}\right)$ memerlukan 0,5 butir telur. Kapasitas telur adalah 24 butir.

Fungsi Batasan-batasan (kendala) adalah sebagai berikut :

1) $X_{1}+X_{2} \leq 30$

2) $X_{1}+0,5 X_{2} \leq 24$

Tabel 3. Jenis Produk, Kapasitas dan Keuntungan

\begin{tabular}{|c|c|c|c|}
\hline \multirow[b]{2}{*}{ Bahan Baku } & \multicolumn{2}{|c|}{ Jenis Produk } & \multirow{2}{*}{$\begin{array}{c}\text { Kapasitas } \\
\text { (buah/butir) }\end{array}$} \\
\hline & $\begin{array}{l}\text { Sostel Besar } \\
\text { (buah/butir) }\end{array}$ & $\begin{array}{l}\text { Sostel Kecil } \\
\text { (buah/butir) }\end{array}$ & \\
\hline Sosis & 1 & 1 & 30 \\
\hline Telur & 1 & 0,5 & 24 \\
\hline Keuntungan & 2.500 & 1.500 & \\
\hline
\end{tabular}

\subsection{Solusi Maksimum Program Linear Metode Simpleks}

Berdasarkan data yang ada pada Tabel 3 dapat dihitung maksimum data sebagai berikut :

a. Fungsi tujuan diubah menjadi fungsi implisit yaitu dengan menggeser elemen dari sebelah kanan ke sebelah kiri, sehingga fungsi tujuan berubah menjadi : $\mathrm{Z}-2500 \mathrm{X}_{1}-1500 \mathrm{X}_{2}=0$ 
b. Fungsi batasan diubah dengan memberikan variabel slack yang berguna untuk mengetahui batasan-batasan dalam kapasitas dengan menambah variabel tambahan menjadi :

1) $X_{1}+X_{2} \leq 30$ diubah menjadi $X_{1}+X_{2}+S_{1} \quad=30$

2) $X_{1}+0,5 X_{2} \leq 24$ diubah menjadi $X_{1}+0,5 X_{2}+S_{2}=24$

Persamaan-persamaan di atas disusun dalam tabel simpleks. Setelah formulasi diubah kemudian disusun ke dalam variabel literasi pertama sebagai berikut :

Tabel 4. Formulasi

\begin{tabular}{ccccccc}
\hline $\begin{array}{c}\text { Variabel } \\
\text { Dasar }\end{array}$ & $\mathbf{Z}$ & $\mathbf{X}_{\mathbf{1}}$ & $\mathbf{X}_{\mathbf{2}}$ & $\mathbf{S}_{\mathbf{1}}$ & $\mathbf{S}_{\mathbf{2}}$ & $\mathbf{N K}$ \\
\hline $\mathrm{Z}$ & 1 & -2500 & -1500 & 0 & 0 & 0 \\
$\mathrm{~S}_{1}$ & 0 & 1 & 1 & 1 & 0 & 30 \\
$\mathrm{~S}_{2}$ & 0 & 1 & 0,5 & 0 & 1 & 24 \\
\hline
\end{tabular}

c. Memilih kolom kunci, yaitu bilangan negatif terbesar pada garis fungsi tujuan.

Tabel 5. Kolom Kunci

\begin{tabular}{ccccccc}
\hline $\begin{array}{c}\text { Variabel } \\
\text { Dasar }\end{array}$ & $\mathbf{Z}$ & $\mathbf{X}_{\mathbf{1}}$ & $\mathbf{X}_{\mathbf{2}}$ & $\mathbf{S}_{\mathbf{1}}$ & $\mathbf{S}_{\mathbf{2}}$ & $\mathbf{N K}$ \\
\hline $\mathrm{Z}$ & 1 & -2500 & -1500 & 0 & 0 & 0 \\
$\mathrm{~S}_{1}$ & 0 & 1 & 1 & 1 & 0 & 30 \\
$\mathrm{~S}_{2}$ & 0 & 1 & 0,5 & 0 & 1 & 24 \\
\hline
\end{tabular}

d. Memilih baris kunci, yaitu nilai yang memiliki limit rasio dengan angka positif terkecil. Limit rasio diperoleh dari nilai kanan (NK) dibagi dengan nilai kolom kunci. Kemudian perpotongan antara kolom kunci dan baris kunci merupakan angka kunci.

Tabel 6. Baris Kunci dan Angka Kunci

\begin{tabular}{cccccccc}
\hline $\begin{array}{c}\text { Variabel } \\
\text { Dasar }\end{array}$ & $\mathbf{Z}$ & $\mathbf{X}_{\mathbf{1}}$ & $\mathbf{X}_{\mathbf{2}}$ & $\mathbf{S}_{\mathbf{1}}$ & $\mathbf{S}_{\mathbf{2}}$ & $\mathbf{N K}$ & $\begin{array}{c}\text { Limit } \\
\text { Rasio }\end{array}$ \\
\hline $\mathrm{Z}$ & 1 & -2500 & -1500 & 0 & 0 & 0 & 0 \\
$\mathrm{~S}_{1}$ & 0 & 1 & 1 & 1 & 0 & 30 & 30 \\
$\mathrm{~S}_{2}$ & 0 & $\mathbf{1}$ & 0,5 & 0 & 1 & 24 & 24 \\
\hline
\end{tabular}

Kolom $\mathrm{X}_{1} \quad=$ Kolom Kunci

Baris $\mathrm{S}_{2} \quad=$ Baris Kunci

Angka $1=$ Angka Kunci

e. Mengubah nilai pada baris kunci. Semua nilai pada baris $S_{2}$ dibagi dengan 1 (angka kunci).
1) $0 / 1=0$
3) $0,5 / 1=0,5$
5) $1 / 1=1$
2) $1 / 1=1$
4) $0 / 1=0$
6) $24 / 1=24$

Hasil pembagian tersebut dimasukkan pada baris baru yaitu baris $\mathrm{S}_{2}$ yang telah diubah menjadi $\mathrm{X}_{1}$, karena $\mathrm{X}_{1}$ merupakan kolom kunci.

Tabel 7. Perubahan Baris Kunci

\begin{tabular}{ccccccc}
\hline $\begin{array}{c}\text { Variabel } \\
\text { Dasar }\end{array}$ & $\mathbf{Z}$ & $\mathbf{X}_{\mathbf{1}}$ & $\mathbf{X}_{\mathbf{2}}$ & $\mathbf{S}_{\mathbf{1}}$ & $\mathbf{S}_{\mathbf{2}}$ & $\mathbf{N K}$ \\
\hline $\mathrm{Z}$ & 1 & -2500 & -1500 & 0 & 0 & 0 \\
$\mathrm{~S}_{1}$ & 0 & 1 & 1 & 1 & 0 & 30 \\
$\mathrm{X}_{1}$ & 0 & $\mathbf{1}$ & 0,5 & 0 & 1 & 24 \\
\hline
\end{tabular}

f. Mengubah nilai-nilai selain pada baris kunci. Baris baru = baris lama - (koefisien per kolom kunci * nilai baris kunci).

Baris $\mathbf{Z}$

\begin{tabular}{lcccccccl} 
Baris Lama & & {[} & -2500 & -1500 & 0 & 0 & 0 & ] \\
NBBK & -2500 & {[} & 1 & 0,5 & 0 & 1 & 24 & ] \\
\hline Baris Baru & & 0 & -250 & 0 & 2500 & 60000
\end{tabular}

Baris $\mathbf{S}_{1}$ 


\begin{tabular}{lllllllll} 
Baris Lama & & {[} & 1 & 1 & 1 & 0 & 30 & ] \\
NBBK & 1 & {[} & 1 & 0,5 & 0 & 1 & 24 & ] \\
\hline
\end{tabular}

$\begin{array}{lllllll}\text { Baris Baru } & 0 & 0,5 & 1 & -1 & 6\end{array}$

Tabel 8. Hasil Optimasi

\begin{tabular}{ccccccc}
\hline $\begin{array}{c}\text { Variabel } \\
\text { Dasar }\end{array}$ & $\mathbf{Z}$ & $\mathbf{X}_{\mathbf{1}}$ & $\mathbf{X}_{\mathbf{2}}$ & $\mathbf{S}_{\mathbf{1}}$ & $\mathbf{S}_{\mathbf{2}}$ & $\mathbf{N K}$ \\
\hline $\mathrm{Z}$ & 1 & 0 & -250 & 0 & 2500 & $\mathbf{6 0 0 0 0}$ \\
$\mathrm{S}_{1}$ & 0 & 0 & 0,5 & 1 & -1 & $\mathbf{6}$ \\
$\mathrm{X}_{1}$ & 0 & 1 & 0,5 & 0 & 1 & $\mathbf{2 4}$ \\
\hline
\end{tabular}

Untuk menentukan keuntungan maksimum, tidak boleh ada angka negatif pada garis fungsi tujuan. Berdasarkan tabel di atas, masih terdapat nilai negatif pada garis fungsi tujuan sehingga masih harus dilakukan literasi kedua yaitu pada kolom $\mathrm{X}_{2}$.

g. Menentukan kolom kunci, baris kunci, dan angka kunci literasi kedua.

Tabel 9. Kolom Kunci, Baris Kunci, dan Angka Kunci Literasi Kedua

\begin{tabular}{cccccccc}
\hline $\begin{array}{c}\text { Variabel } \\
\text { Dasar }\end{array}$ & $\mathbf{Z}$ & $\mathbf{X}_{\mathbf{1}}$ & $\mathbf{X}_{\mathbf{2}}$ & $\mathbf{S}_{\mathbf{1}}$ & $\mathbf{S}_{\mathbf{2}}$ & $\mathbf{N K}$ & $\begin{array}{c}\text { Limit } \\
\text { Rasio }\end{array}$ \\
\hline $\mathrm{Z}$ & 1 & 0 & -250 & 0 & 2500 & 60000 & -240 \\
$\mathrm{~S}_{1}$ & 0 & 0 & $\mathbf{0 , 5}$ & 1 & -1 & 6 & 12 \\
$\mathrm{X}_{1}$ & 0 & 1 & 0,5 & 0 & 1 & 24 & 48 \\
\hline
\end{tabular}

h. Mengubah nilai pada baris kunci. Semua nilai pada baris $S_{1}$ dibagi dengan 0,5 (angka kunci).
1) $0 / 0,5=0$
3) $0,5 / 0,5=1$
5) $-1 / 0,5=-2$
2) $0 / 0,5=0$
4) $1 / 0,5=2$
6) $6 / 0,5=12$

Hasil pembagian dimasukkan pada baris baru yaitu baris $\mathrm{S}_{1}$ yang telah diubah menjadi $\mathrm{X}_{2}$.

Tabel 10. Perubahan Baris Kunci

\begin{tabular}{ccccccc}
\hline $\begin{array}{c}\text { Variabel } \\
\text { Dasar }\end{array}$ & $\mathbf{Z}$ & $\mathbf{X}_{\mathbf{1}}$ & $\mathbf{X}_{\mathbf{2}}$ & $\mathbf{S}_{\mathbf{1}}$ & $\mathbf{S}_{\mathbf{2}}$ & $\mathbf{N K}$ \\
\hline $\mathrm{Z}$ & 1 & 0 & -250 & 0 & 2500 & 60000 \\
$\mathrm{X}_{2}$ & 0 & 0 & 1 & 2 & -2 & 12 \\
$\mathrm{X}_{1}$ & 0 & 1 & 0,5 & 0 & 1 & 24 \\
\hline
\end{tabular}

i. Mengubah nilai-nilai selain pada baris kunci. Baris baru = baris lama - (koefisien per kolom kunci * nilai baris kunci).

Baris Z

\begin{tabular}{lcccccccl} 
Baris Lama & & {[} & 0 & -250 & 0 & 2500 & 60000 & ] \\
NBBK & -250 & {[} & 0 & 1 & 2 & -2 & 12 & ] \\
\hline Baris Baru & & & 0 & 0 & 500 & 2000 & 63000
\end{tabular}

Baris Baru $\quad 0 \quad 0 \quad 500 \quad 2000 \quad 63000$

Baris $\mathbf{X}_{1}$

\begin{tabular}{lllllllll} 
Baris Lama & & {[} & 1 & 0,5 & 0 & 1 & 24 & ] \\
NBBK & 0,5 & {[} & 0 & 1 & 2 & -2 & 12 & ] \\
\hline Baris Baru & & & 1 & 0 & -1 & 2 & 18
\end{tabular}

Tabel 11. Hasil Optimasi

\begin{tabular}{ccccccc}
\hline $\begin{array}{c}\text { Variabel } \\
\text { Dasar }\end{array}$ & $\mathbf{Z}$ & $\mathbf{X}_{\mathbf{1}}$ & $\mathbf{X}_{\mathbf{2}}$ & $\mathbf{S}_{\mathbf{1}}$ & $\mathbf{S}_{\mathbf{2}}$ & $\mathbf{N K}$ \\
\hline $\mathrm{Z}$ & 1 & 0 & 0 & 500 & 2000 & $\mathbf{6 3 0 0 0}$ \\
$\mathrm{X}_{2}$ & 0 & 0 & 1 & 2 & -2 & $\mathbf{1 2}$ \\
$\mathrm{X}_{1}$ & 0 & 1 & 0 & -1 & 2 & $\mathbf{1 8}$ \\
\hline
\end{tabular}


Berdasarkan Tabel 11 di atas, baris Z tidak lagi ada yang bernilai negatif, sehingga solusi yang diperoleh sudah optimal. Maka keuntungan maksimum yang diperoleh UMKM Sosis Bu Tinuk dalam satu hari dari perhitungan dengan metode simpleks adalah Rp 63.000,00 dengan memproduksi Sostel besar $\left(\mathrm{X}_{1}\right)$ sebanyak 18 buah dan Sostel kecil $\left(\mathrm{X}_{2}\right)$ sebanyak 12 buah.

\subsection{Solusi Maksimum Program Linear Menggunakan POM-QM}

Gambar 2 merupakan hasil pemecaham program linear metode simpleks menggunakan POM-QM.

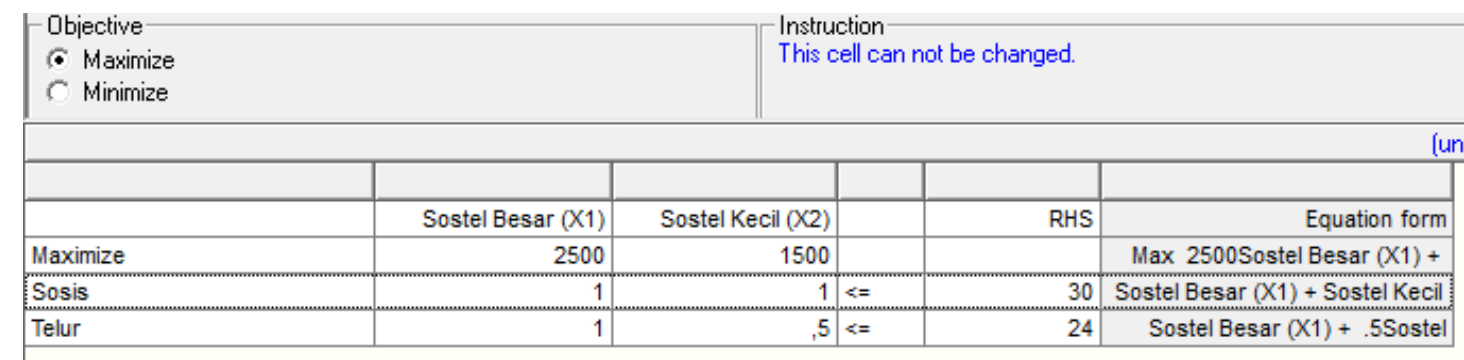

Gambar 2. Tampilan Masukkan Data Produksi

Setelah data selesai dimasukkan kemudian pilih tombol solve lalu pilih menu Iterations kemudian Solution List. Maka akan diperoleh solusi pemecahan persoalan linear programming dengan metode Simpleks sebagai berikut.

\begin{tabular}{|c|c|c|c|c|c|c|}
\hline $\mathrm{Cj}$ & $\begin{array}{r}\text { Basic } \\
\text { Variables }\end{array}$ & $\begin{array}{r}2500 \\
\text { Sostel }\end{array}$ & $\begin{array}{r}1500 \\
\text { Sostel Kecil }\end{array}$ & $\begin{array}{r}0 \\
\text { slack } 1\end{array}$ & $\begin{array}{r}0 \\
\text { slack } 2\end{array}$ & Quantity \\
\hline \multicolumn{7}{|c|}{ Iteration 1} \\
\hline 0 & slack 1 & 1 & 1 & 1 & 0 & 30 \\
\hline \multirow[t]{3}{*}{0} & slack 2 & 1 & 0,5 & 0 & 1 & 24 \\
\hline & $z j$ & 0 & 0 & 0 & 0 & 0 \\
\hline & $c j-z j$ & 2.500 & 1.500 & 0 & 0 & \\
\hline \multicolumn{7}{|c|}{ Iteration 2} \\
\hline 0 & slack 1 & 0 & 0,5 & 1 & -1 & 6 \\
\hline \multirow[t]{3}{*}{2500} & Sostel & 1 & 0,5 & 0 & 1 & 24 \\
\hline & $\mathrm{zj}$ & 2500 & 1250 & 0 & 2500 & 60.000 \\
\hline & $c j-z j$ & 0 & 250 & 0 & -2.500 & \\
\hline \multicolumn{7}{|c|}{ Iteration 3} \\
\hline 1500 & Sostel Kecil & 0 & 1 & 2 & -2 & 12 \\
\hline \multirow[t]{3}{*}{2500} & Sostel & 1 & 0 & -1 & 2 & 18 \\
\hline & $\mathrm{zj}$ & 2500 & 1500 & 500 & 2000 & 63.000 \\
\hline & cj-zj & 0 & 0 & -500 & -2.000 & \\
\hline
\end{tabular}

Gambar 3. Tampilan Literasi Data Produksi

\begin{tabular}{|l|r|r|}
\hline Variable & Status & Value \\
\hline Sostel Besar (X1) & Basic & 18 \\
\hline Sostel Kecil (X2) & Basic & 12 \\
\hline slack 1 & NONBasic & 0 \\
\hline slack 2 & NONBasic & 0 \\
\hline Optimal Value $(Z)$ & & 63000 \\
\hline
\end{tabular}

Gambar 4. Tampilan Solusi Pemecahan Masalah

Hasil analisis menunjukkan bahwa penerapan Program Linear dengan menggunakan POM-QM dalam optimasi UMKM Sosis $\mathrm{Bu}$ Tinuk dapat membantu dalam menghitung keuntungan maksimum dengan cepat dan tepat dari keterbatasan bahan baku yang dimiliki.

Hasil analisis menunjukkan bahwa perhitungan keuntungan maksimum menggunakan Program Linear metode simpleks dengan perhitungan pada POM-QM memiliki hasil yang sama, yakni keuntungan maksimum UMKM Sosis Bu Tinuk dalam satu hari mencapai angka Rp 63.000,00 dengan memproduksi sostel besar $\left(\mathrm{X}_{1}\right)$ sebanyak 18 buah dan sostel kecil $\left(\mathrm{X}_{2}\right)$ sebanyak 12 buah. 


\section{KESIMPULAN}

Berdasarkan hasil pembahasan di atas, dapat ditarik kesimpulan, yaitu :

1. Program Linier metode simpleks dapat diterapkan dalam optimasi UMKM Sosis Bu Tinuk dalam memaksimalkan keuntungan dari keterbatasan bahan baku yang dimiliki.

2. POM-QM dapat membantu dalam meningkatkan perhitungan keuntungan maksimal secara cepat, tepat dan efisien.

3. Keuntungan maksimal yang diperoleh yaitu sebesar Rp 63.000,00 setiap harinya dengan memproduksi sostel besar sebanyak 18 buah dan sostel kecil sebanyak 12 buah.

4. UMKM Sosis milik Bu Tinuk belum mencapai keuntungan maksimum, karena dalam satu kali produksi hanya memproduksi sostel besar 15 buah dan sostel kecil 15 buah dengan keuntungan per hari kurang lebih Rp 60.000,00.

\section{REFERENCES}

[1] A. Saryoko, "Metode Simpleks Dalam Optimalisasi Hasil Produksi," Informatics for Educators and Professionals, vol. 1, no 1, pp. 27-36, 2016.

[2] I. B. M. A. Dwijateneya, Syahrani, and N. Cristia "Optimalisasi Usaha Kerupuk Ikan: Analisis Linier Programming Dengan Metode Simpleks," Gerbang Etam, vol. 12, no 1, pp. 18-30, 2018.

[3] T. Chandra, "Penerapan Algoritma Simpleks dalam Aplikasi Penyelesaian Masalah Program Linier," TIMES, vol. IV, no. 1, pp. $18-21,2015$.

[4] Eliatun and T. Darmansyah, "Pengembangan Perumahan Dengan Desain Konstruksi Di Lahan Basah Pada Wilayah Kota Banjarmasin Menggunakan Riset Operasi," GRADASI Tek. SIPIL, vol. 2, no. 1, pp. 69-75, 2018.

[5] M. S. Rumetna et al., "Pemanfaatan POM-QM Untuk Menghitung Keuntungan Maksimum UKM Aneka Cipta Rasa (ACR) Menggunakan Metode Simpleks," GEOTIK, pp. 12-22. 2019.

[6] R. Ong et al., "Maksimalisasi Keuntungan Pada Usaha Dagang Martabak Sucipto Menggunakan Metode Simpleks Dan POMQM," Jurikom., vol. 6, no. 4, pp. 434-441, 2019.

[7] Z. Nasution et al., "PENERAPAN METODE SIMPLEKS UNTUK MENGANALISA PERSAMAAN LINIER DALAM MENGHITUNG KEUNTUNGAN MAKSIMUM," Jurikom., vol. 3, no. 4, pp. 42-48, 2016.

[8] M. S. Rumetna, T. N. Lina, T. Aponno, A. Palisoa, and F. Singgir, "Penerapan Metode Simpleks Dan Software POM- QM Untuk Optimalisasi Hasil Penjualan Pentolan Bakso," Ilm. Manaj. Inform. dan Komp., vol. 02, no. 03, pp. 143-149, 2018.

[9] M. R. Aulia et al., "MAKSIMALISASI KEUNTUNGAN DENGAN PENDEKATAN METODE SIMPLEKS Studi Kasus pada Pabrik Sendal X di Ciputat, Tangerang Selatan," Jurnal Liquidity, vol. 2, no. 3, pp. 114-150, 2013.

[10] S. Suryabrata, "Metodologi Penelitian". Jakarta: PT. Raja Grafindo Persada, 2008. 